\title{
Antiinflammatory and Antiproliferative Activity of Naphthoxazole, Fused Hetero-benzoxazole and Bridged Benzobicyclic Photoproducts
}

\author{
Ivana Šagud, ${ }^{1}$ Ana Ratković, ${ }^{1}$ Matea Cedilak, ${ }^{2}$ Ivo Zlatar, ${ }^{2}$ Martina Bosnar, ${ }^{2, *}$ Vanja Kelava, ${ }^{3}$ Irena Škorić ${ }^{1, *}$
}

\author{
Department of Organic Chemistry, Faculty of Chemical Engineering and Technology, University of Zagreb, Marulićev trg 19, HR-10000 Zagreb, Croatia \\ 2 Pharmacology in vitro, Fidelta Ltd., Prilaz baruna Filipovića 29, HR-10000 Zagreb, Croatia \\ 3 Drug metabolism and Pharmacokinetics, Fidelta Ltd., Prilaz baruna Filipovića 29, HR-10000 Zagreb, Croatia \\ * Authors' e-mail addresses: Martina.Bosnar@glpg.com; iskoric@fkit.hr
}

RECEIVED: May 21, 2019 * REVISED: July 19, 2019 * ACCEPTED: July 21, 2019

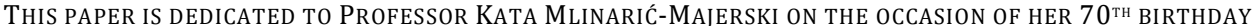

Abstract: Biological activity of naphthoxazoles, fused hetero-benzoxazoles and benzobicyclo[3.2.1]-derivatives was investigated in proliferation and inflammation based assays. The tested compounds were prepared by photocylization or photocycloaddition reactions. Effect of compounds on proliferation of several cancer cell lines was determined by measuring cell metabolic activity through time. Lipopolysaccharide (LPS) stimulation of peripheral blood mononuclear cells (PBMC) was used to investigate antiinflammatory properties of the compounds. Several naphthoxazoles and fused hetero-benzoxazoles inhibited TNF $\alpha$ protein expression in LPS stimulated PBMC, indicating possible antiinflammatory role which would be interesting to further investigate. Physico-chemical properties of tested compounds have been also studied using chromatographic lipophilicity measure, chrom $\log D$ and $\log P$ was calculated as the importance of physico-chemical properties of compounds at early stage of discovery of new drugs is well established. The similarities in structure and activity of some representative compounds affirm the need to further address their antiinflammatory properties.

Keywords: antiinflammatory activity, antiproliferative activity, benzobicyclo[3.2.1]octadiene, biological activity, hetero-benzoxazole, naphthoxazole, physico-chemical properties.

\section{INTRODUCTION}

$\mathbf{H}$ ETEROCYCLIC compounds are the most widely used class in pharmaceutical and agrochemical industries. They exhibit numerous biological activities, among which are antibacterial, antifungal, antiviral, antiinflammatory, antidepressant etc. ${ }^{[1]}$ For example, pyrazolone derivatives, phenazone, metamizole, aminophenazone, phenyl buta-zone and apazone are non-steroidal antiinflammatory drugs (NSAID) that exhibit antiinflammatory, analgesic and antipyretic activity due to inhibition of cyclooxygenase (COX) enzymes. ${ }^{[2]} \mathrm{Pu}-$ rine analogues, pyrimidine analogues and antifolates are cytostatic compounds that inhibit cell proliferation and are used in cancer treatment, as well as for autoimmune disorders. ${ }^{[3-5]}$ In general the oxazole moiety ${ }^{[6]}$ and the bicyclo[3.2.1]-core ${ }^{[7]}$ are important building blocks for the synthesis of many biologically active molecules. Some of the fused polycyclic compounds with the oxazole ring have shown antibacterial and antituberculosis ${ }^{[8]}$ activities as well as anticancer activitiy ${ }^{[9]}$ and some have been tested for antioxidant activity. ${ }^{[10]}$ Compounds with the bicyclo[3.2.1]skeleton are potent inhibitors of dopamine and serotonin transporters and they have crutial role in treatment of central nervous system (CNS) and Alzheimer's disorders. ${ }^{[11]}$ In our group, a whole library of both groups of these polycylic compounds was obtained by utilization of the photochemical synthesis. ${ }^{[12-16]}$ Naphthoxazoles as a group of compounds have been known since Fisher synthesized 2methylnaphtho[1,2- $d$ ]oxazole and 2-methylnaphtho[2,1d] oxazoles in 1906. ${ }^{[17]}$ In the following years many synthetic approaches were developed for the synthesis of these compounds. ${ }^{[18]}$ The synthesis of naphthoxazoles ${ }^{[19]}$ and 


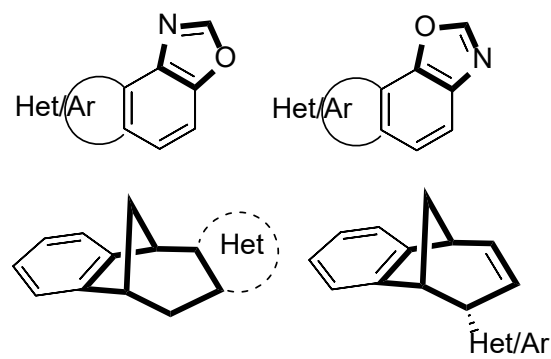

Figure 1. General structures of the investigated compounds.

fused hetero-benzoxazoles ${ }^{[19,20]}$ (Figure 1) in one photocyclization step by utilising light as a very clean reagent gave a new and easy path to this kind of polycyclic systems that are taxing to obtain via ground state organic synthesis. Syntheses of compounds containing bicy-clo[3.2.I]octane and bicyclo[3.2.I]octadiene core (Figure 1) are also documented in the literature. ${ }^{[21]}$ Bicyclo[3.2.I]-skeleton can be constructed using different synthetic pathways, one of which is the photochemical cycloaddition approach that has been developed by our group in batch and flow photochemical reactor. ${ }^{[22-34]}$

Guided by all above mentioned compounds, we have selected 32 compounds from both types of photoproducts and investigated their biological activity in proliferation and inflammation based assays. Effect of compounds on proliferation of several cancer cell lines was determined by measuring cell metabolic activity through time. On the other hand, lipopolysaccharide (LPS) stimulation of peripheral blood mononuclear cells (PBMC) was used to investigate antiinflammatory properties of the compounds.

Physico-chemical properties of tested compounds have been studied using chromatographic lipophilicity measure, chrom $\log D$ and $\log P$ was calculated. The importance of physico-chemical properties of compounds at early stage of discovery of new drugs is now well established. ${ }^{[35-37]}$ Lipophilicity measurements by reverse phase chromatography have been already proven as fast and efficient method for compound profiling in the early phase of optimization and results are expressed as Chromatographic $\log D($ chrom $\log D) .{ }^{[38-40]}$ In this paper we analysed also the physico-chemical properties of the tested compounds as possible reason for their biological activity.

\section{EXPERIMENTAL SECTION}

\section{Chemistry}

Investigated naphthoxazoles, fused hetero-benzoxazoles and benzobicyclo[3.2.1]-derivatives were previously synthesized and completely characterized. ${ }^{[14,15,19,20,22]}$ They were prepared by photocylization or [2+2]-photocycloaddition reactions from corresponding starting materials in very good yields. The required styryloxazoles were synthesized in one step by Van Leusen reaction from aryl / heteroaryl substituted $\alpha, \beta$-unsaturated aldehydes and tosylmethyl isocynide (TosMIC). In the case of synthesis of $2 / 3$ thienylethenyl- and 2/3/4-pyridylethenyloxazoles the necessary unsaturated aldehydes were prepared by Wittig reaction from the corresponding aldehydes and formylmethylenetriphenylphosphorane.

\section{Chrom $\log D$ Determination}

Chrom $\log D$ values were determined from the following equation: chrom $\log D=0.0857 \times \mathrm{CHI}-2$ (ref. Chromatographic Hydrophobic Index (CHI) values have been determined from gradient retention times (tR) as described by Valkó and Slegel. ${ }^{[41,42]}$ These values approximately correspond to the volume percentage of organic component in the mobile phase when the compound elutes. $\mathrm{CHI}$ values were determined at $\mathrm{pH}$ 7.4. Chromatograms were obtained using an Agilent 1100 Series HPLC instruments equipped with diode array detector (DAD) coupled with Micromass Quattro API mass spectrometer. Data acquisition and processing were performed with MassLynx software version 4.1. The column used for $\mathrm{CHI}$ determination was Luna $\mathrm{C} 18(50 \mathrm{~mm} \times$ $3 \mathrm{~mm}$ i.d., $5 \mu \mathrm{m}$ particle size, $100 \AA$ A). The aqueous part of the mobile phase was $50 \mathrm{mM}$ ammonium acetate adjusted with ammonia solution to $\mathrm{pH} 7.4$. As an organic part of their mobile phase acetonitrile was used. The mobile phase flow rate was $1 \mathrm{~mL} \mathrm{min-1}$ for all measurements. The gradient retention times $t R$ were measured under the following gradient condition: 0 to 3 min linear gradient from 0 to 100 $\%$ acetonitrile; 3 to $3.5 \mathrm{~min} 100 \%$ acetonitrile; 3.5 to 3.7 min from 100 to $0 \%$ acetonitrile; and 3.7 to $5 \mathrm{~min}$ reequilibration time with $100 \%$ of aqueous part of the mobile phase.

\section{Biological Activity}

Effect of compounds on cell proliferation was determined in cancer cell lines THP-1, Jurkat and HL-60. The assay is based on ability of metabolically active cells to convert MTS tetrazolium compound to formazan product detectable by absorbance at $490 \mathrm{~nm}$. The quantity of formazan product is proportional to the number of metabolically active cells. In this assay staurosporine was used as reference compound since it is a protein kinases inhibitor which induces apoptosis. Furthermore, antiinflammatory activity of compounds was determined in LPS stimulated PBMC assay. LPS is one of the components of Gram-negative bacteria cell wall and is recognized by Toll-like receptor 4 (TLR4). The activation of TLR4 signaling induces release of cytokines among which are interleukin-8 (IL-8) and tumor necrosis factor $\alpha(T N F \alpha)$, therefore leading to inflammatory response. In this assay, a widely used corticosteroid 
dexamethasone was used as reference compound because of it's antiinflammatory activity.

\section{Cell Culture}

Human cell lines THP-1 (TIB-202) and Jurkat (TIB152) were purchased from ATCC, while human cell line HL-60 (CCL240) was purchased from ECACC. All cell lines were maintained in cell culture in RPMI medium (Lonza) supplemented with $10 \%$ heat inactivated fetal bovine serum (FBS) (BioWest) in $\mathrm{CO}_{2}$ incubator $\left(5 \% \mathrm{CO}_{2}, 95 \%\right.$ humidity, $\left.37^{\circ} \mathrm{C}\right)$.

\section{Cell Proliferation Assay}

Effect of compounds on proliferation of THP-1, Jurkat and HL-60 cells was determined using CellTiter 96 Aqueous One Solution Cell Proliferation Assay (Promega).

96-well plates were seeded with $30000 \mathrm{HL}-60$, THP1 or Jurkat cells per well, followed by addition of three fold serial dilutions of test compounds using Mosquito instrument (TTP labtech). Staurosporine (Sigma) was used as reference compound. Final testing concentrations of test compounds were $30 \mu \mathrm{M}$ to $13.72 \mathrm{nM}$, while of staurosporine was from $1 \mu \mathrm{M}$ to $0.46 \mathrm{nM}$. Vehicle contained $0.3 \%$ DMSO. Cells treated with compounds or vehicle were incubated for $24 \mathrm{~h}, 48 \mathrm{~h}$ and $72 \mathrm{~h}$ in $\mathrm{CO}_{2}$ incubator $\left(5 \% \mathrm{CO}_{2}, 95 \%\right.$ humidity, $\left.37{ }^{\circ} \mathrm{C}\right)$ after which CellTiter 96 Aqueous One Solution Cell Proliferation Assay substrate was added following manufacturer's instructions. After $4 \mathrm{~h}$ of incubation with the substrate, absorbance at $490 \mathrm{~nm}$ was measured using EnVision 2104 instrument (Perkin Elmer).

\section{LPS Stimulation Assay}

Human peripheral blood mononuclear cells (PBMC) were isolated from healthy volunteer's blood obtained from the Croatian Institute for Transfusion Medicine. Blood was diluted 1:1 with PBS and PBMCs were isolated by centrifugation in Lymphoprep (Axis-Shield) density gradient. 96-well plates were seeded with 200000 PBMCs per well in RPMI 1640 (Lonza) medium supplemented with $10 \%$ FBS (Sigma). Cells were incubated with three fold serial dilutions of test compounds for $1 \mathrm{~h}$ in $\mathrm{CO}_{2}$ incubator ( $5 \% \mathrm{CO}_{2}, 95 \%$ humidity, $37{ }^{\circ} \mathrm{C}$ ), followed by overnight stimulation with $1 \mathrm{ng} / \mathrm{mL}$ of LPS from $E$. coli 0111:B4 (Sigma) in $\mathrm{CO}_{2}$ incubator. Final testing concentrations of test compounds were $30 \mu \mathrm{M}$ to $13.72 \mathrm{nM}$. Dexamethasone was used as reference compound and it was tested from 1 $\mu \mathrm{M}$ to $0.46 \mathrm{nM}$. $0.3 \%$ DMSO was used as vehicle. After overnight incubation, concentrations of TNF $\alpha$ and IL8 were determined in cell supernatants using 384-well format sandwich Elisa assay. Lumitrac 600 microplates (Greiner) were coated with $1 \mu \mathrm{g} / \mathrm{mL}$ of TNF $\alpha$ capture antibody (R\&D Systems) or $2.5 \mu \mathrm{g} / \mathrm{mL}$ of IL8 capture antibody (R\&D
Systems). 1\% BSA (Sigma), $5 \%$ sucrose (Kemika) in PBS (Gibco) was used as blocking buffer, while cell supernatants were diluted either $4 \mathrm{x}$ for TNF $\alpha$ analysis or $150 \mathrm{x}$ for IL8 analysis in $1 \%$ BSA in PBS. Furthermore, $250 \mathrm{ng} / \mathrm{mL}$ of TNF $\alpha$ detection antibody (R\&D Systems) or $25 \mathrm{ng} / \mathrm{mL}$ of IL8 detection antibody (R\&D Systems) were used in Elisa assay, while Chemiluminiscence ELISA Substrate (Roche) was used for developing the signals. Luminescent signals were measured using EnVision 2104 Multilabel Reader (Perkin Elmer).

\section{Data Analysis}

Measured absorbance at $490 \mathrm{~nm}$ was used to calculate percentage of cell proliferation for each compound in comparison to vehicle cells using Micorsoft Excel software v2013. Concentrations of TNF $\alpha$ and IL8 were calculated by extrapolation from their standard curves using Micorsoft Excel software v2013. Obtained concentrations were used to calculate percentages of inhibition of each compound by first subtracting average value of vehicle samples from all other samples. Furthermore, percentage of inhibition was calculated using formula: ( 1 - (compound / average of LPS triggered controls)) $\times 100$.

In both assays, logarithm of tested compound concentration in $\mathrm{M}$ was plotted against calculated percentage of inhibition using GraphPad Prism v7.04 software.

\section{RESULTS AND DISCUSSION}

\section{Chemistry}

Investigated naphthoxazoles 1-5 and 12-22, fused heterobenzoxazoles 6-11 and benzobicyclo[3.2.1]-derivatives 2325 and 28-32 (Schemes 1 and 2, Figures 2 and 3) were previously synthesized and completely characterized. ${ }^{[14,15,19,20,22]}$ They were prepared by photocylization or [2+2]-photocycloaddition reaction from the corresponding starting conjugated compounds in very good yields. The required styryloxazoles were synthesized in one step (Scheme 1 ) by Van Leusen reaction from aryl/heteroaryl substituted $\alpha, \beta$-unsaturated aldehydes and tosylmethyl

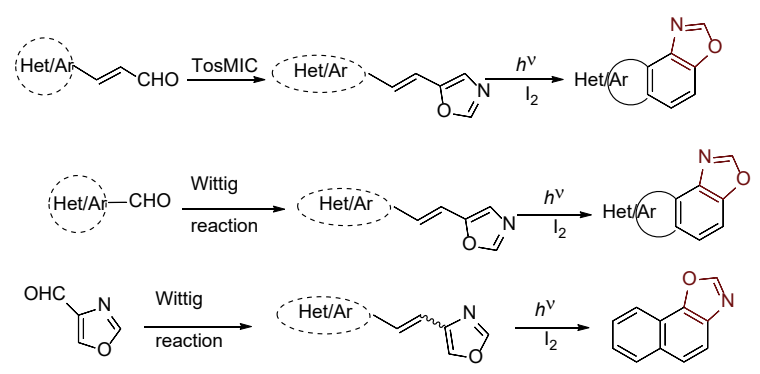

Scheme 1. General scheme for the synthesis of the investigated naphthoxazoles and fused hetero-benzoxazoles. 


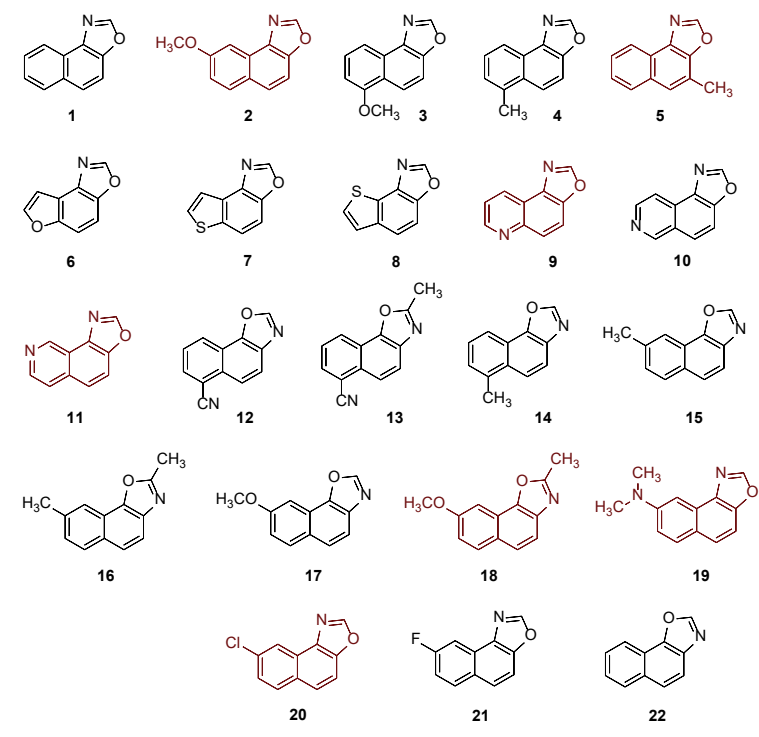

Figure 2. Structures of the investigated naphthoxazoles and fused hetero-benzoxazoles 1-22.

isocynide (TosMIC). The investigated hetero-naphthalene derivatives $\mathbf{2 6}$ and $\mathbf{2 7}$ are also obtained and isolated as photocyclization reaction side-products possessing the potentially interesting structure for biological activity.

In the case of 2/3-thienylethenyl- and 2/3/4-pyri-

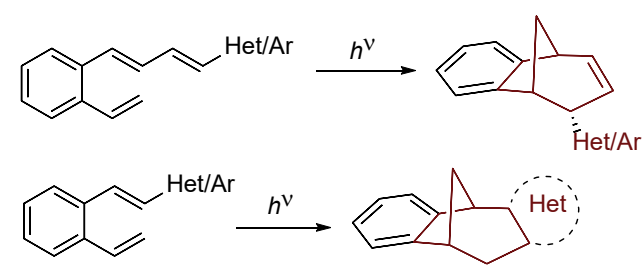

Scheme 2. General schemes for the synthesis of compounds possessing benzobicyclo[3.2.1]-skeleton.

dylethenyloxazoles synthesis the necessary unsatu-rated aldehydes were prepared by Wittig reaction from the corresponding aldehydes and formylmethylenetriphenylphosphorane.

The investigated benzobycyclic photoproducts 2332 were prepared by photocycloaddition of starting conjugated substrates (photoproducts 23-25 and 28-32, Figure 3 ) or by photocyclization reaction (compounds $\mathbf{2 6}$ and 27).

\section{Biology}

As it was mentioned before, 32 compounds were selected belonging to different types of heteropolycyclic photoproducts (Figures 2 and 3 ) and investigated their biological activity in proliferation and inflammation based assays (Figures 4-8). Amongst the tested compounds, naphtha-

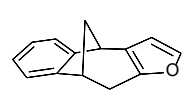

23

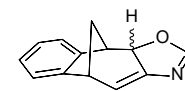

24

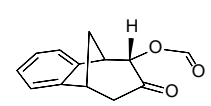

25

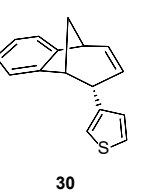

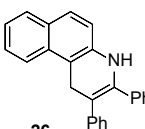
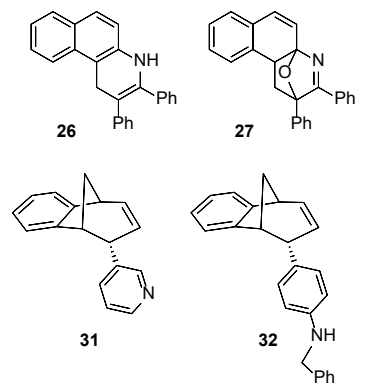

Figure 3. Structures of the investigated benzobycyclic photoproducts 23-32.

Proliferation in HL60 cells

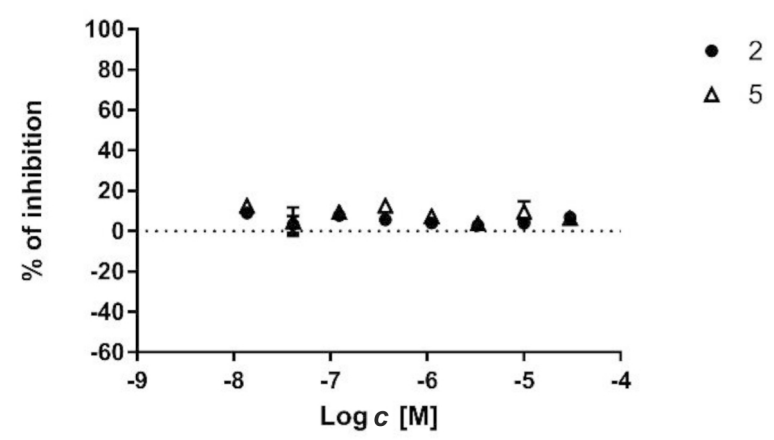

Proliferation in HL60 cells

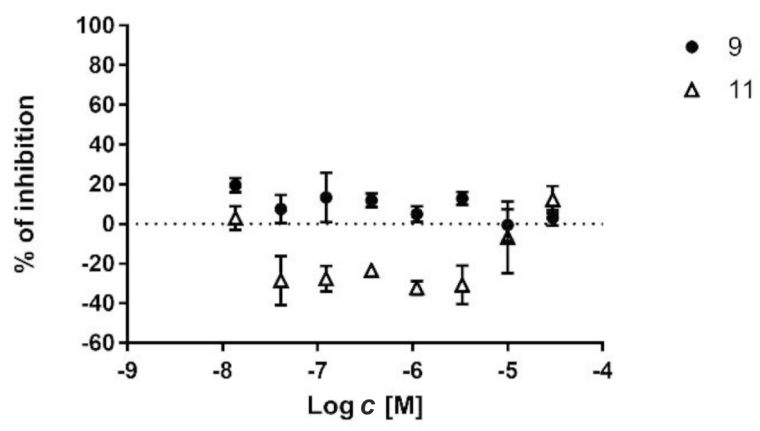

Figure 4. Effect of compounds 2, 5, 9 and 11 on proliferation of HL60 cells after $72 \mathrm{~h}$ of incubation $(n=3)$. 
Proliferation in Jurkat cells

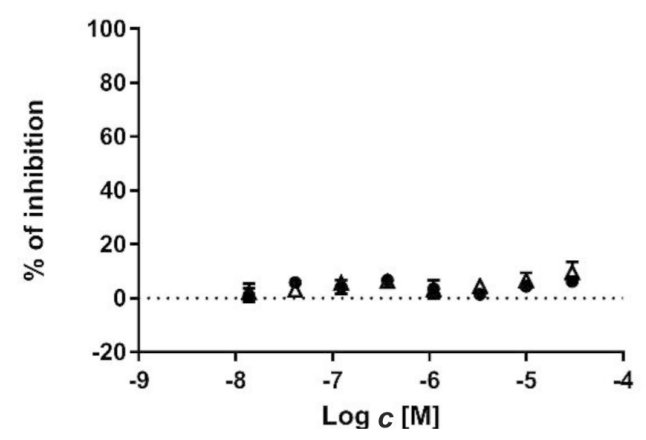

Proliferation in Jurkat cells

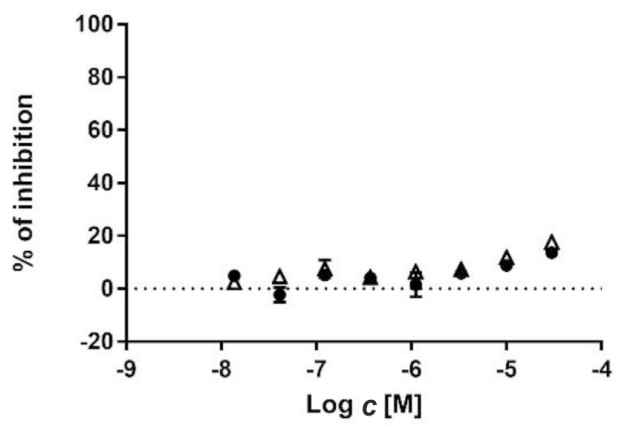

- 9

$\Delta 11$

Figure 5. Effect of compounds 2, 5, 9 and 11 on proliferation of Jurkat cells after $72 \mathrm{~h}$ of incubation $(n=3)$.

Proliferation in THP1 cells

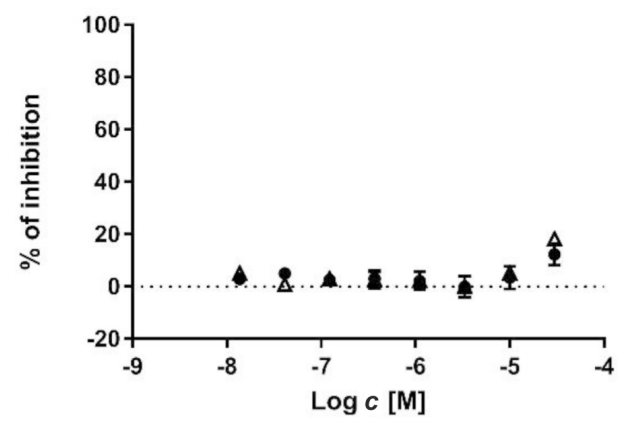

Proliferation in THP1 cells
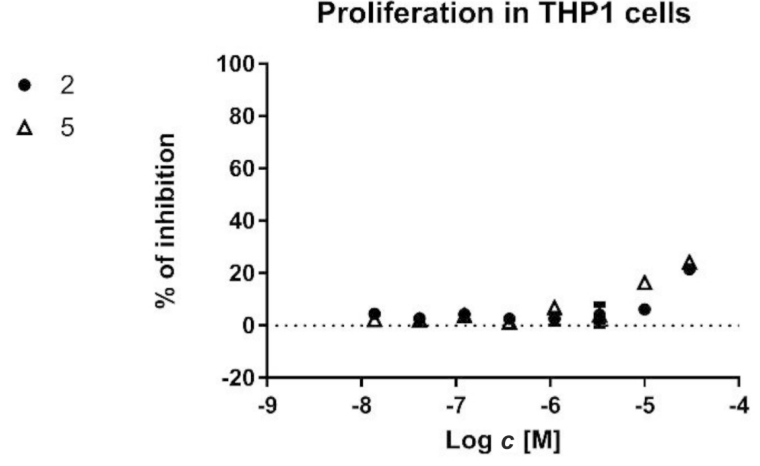

Figure 6. Effect of compounds 2, 5, 9 and 11 on proliferation of THP1 cells after $72 \mathrm{~h}$ of incubation $(n=3)$.

IL8

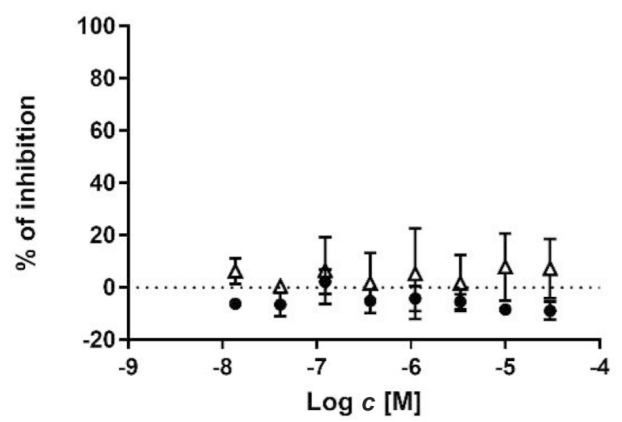

IL8

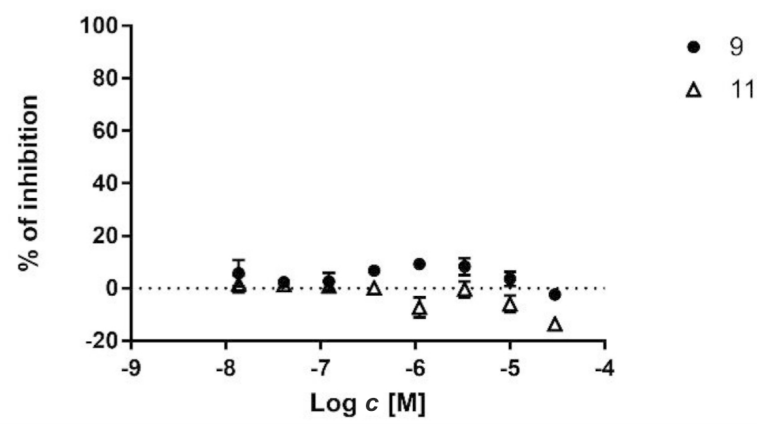

Figure 7. Effect of compounds 2, 5, 9 and 11 on IL8 production in LPS stimulated PBMC $(n=2)$.

xazoles $\mathbf{2}$ and $\mathbf{5}$, and fused hetero-benzoxazoles $\mathbf{9}$ and $\mathbf{1 1}$ inhibited TNF $\alpha$ protein expression in LPS stimulated PBMC (Figures 8 and 9), indicating possible antiinflammatory role which would be interesting to further investigate. On the contrary, these compounds did not show any effect on IL8 (Figure 7) protein expression, another factor playing important role in inflammation. Concerning the exact structure of the tested compounds, naphthoxazoles $\mathbf{2}$ and 5 possess the methoxy or methyl group in the structure at the specific positions of different aromatic rings, while hetero-benzoxazoles $\mathbf{9}$ and $\mathbf{1 1}$ have the condensed pyridine ring instead of the second aryl moiety. That is very important to clarify before the study of physico-chemical properties in general.

Both TNF $\alpha$ and IL8 are mainly produced by macrophages, they promote inflammation and act as neutrophil chemoattractants, while TNF $\alpha$ is also one of the most notable proinflammatory factors in cancer. Furthermore, related compounds 18,19 and 20 with similar structure to compounds 2, 5, 9 and $\mathbf{1 1}$ were also tested in 
TNF $\alpha$

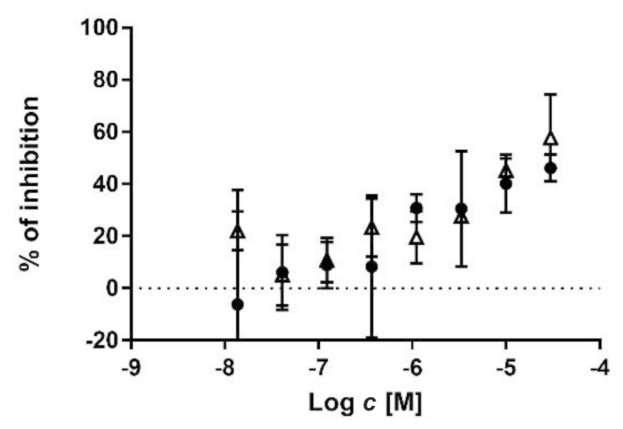

$\mathrm{TNF} \alpha$

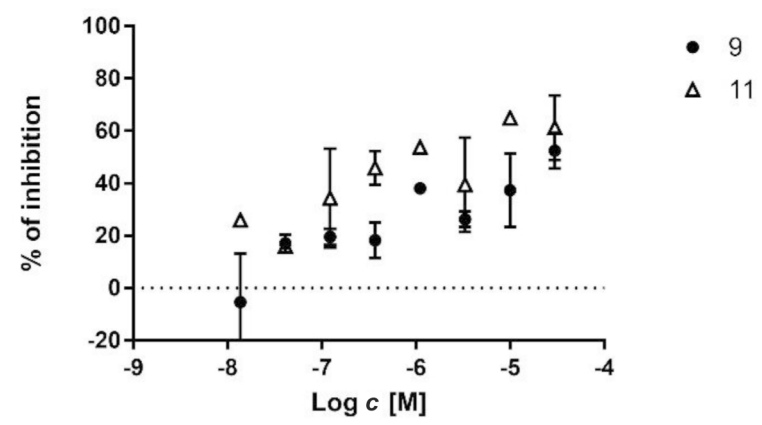

Figure 8. Effect of compounds 2, 5, 9 and 11 on TNFa production in LPS stimulated PBMC $(n=2)$.

TNF $\alpha$

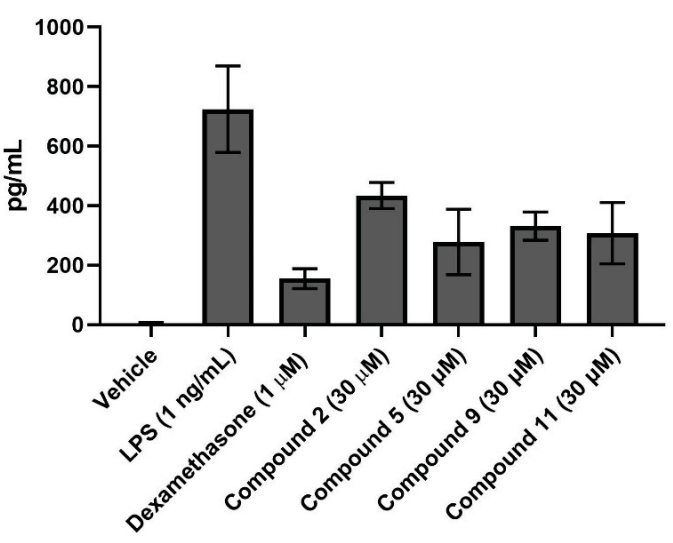

Figure 9. TNF $\alpha$ expression $(\mathrm{pg} / \mathrm{mL})$ in vehicle and LPS (1 $\mathrm{ng} / \mathrm{mL}$ ) stimulated PBMC treated with reference compound dexamethasone and compounds 2, 5, 9 and 11 ( $n=6$ for vehicle and LPS; $n=2$ for compound treatments).

LPS stimulated PBMC assay where they achieved up to 40 $\%$ of TNF $\alpha$ inhibition and again, no effect on IL8 expression
(Supplementary figures 4 and 5). The similarities in structure and activity of these compounds affirm the need to further address their antiinflammatory properties. It is evident that the position on the third (hetero) aromatic ring is very important for the antiinflammatory properties of the compounds (Scheme 3). Compounds 2, 18, 19 and 20 have different substituents on the same position of the condensed third aromatic ring, and on the same position compound $\mathbf{1 1}$ possesses the nitrogen atom. On this way the most important position for the substituents affecting the antiinflammatory activity is defined including the methoxy, dimethylamino, chloro substiturnts or the nitrogen atom as a part of the pyridine moiety (compounds $\mathbf{9}$ and $\mathbf{1 1}$ ) in the structure. Also, the methyl substituent on the middle aromatic ring (compound 5), or between the nitrogen and oxygen atoms in the oxazole ring (in combination with the methoxy substituent, compound 18) showed an important role for the investigated properties.

The effect of compounds on proliferation of several cancer cell lines (THP-1, Jurkat and HL-60) was also investigated. Tested concentrations of compounds did not exhibit any toxic or antiproliferative activity in these assays, during $72 \mathrm{~h}$ of incubation (Figures 4,5 and 6). Some inhibi-

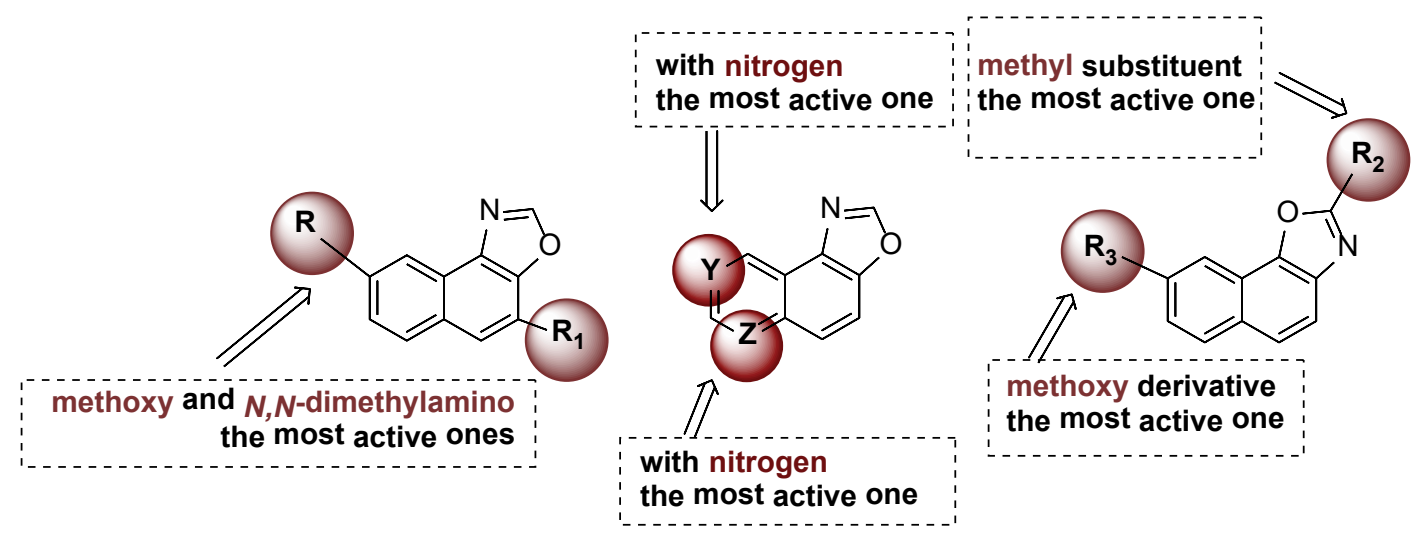

Scheme 3. SAR of naphthoxazole photoproducts concerning antiinflammatory activity. 
A

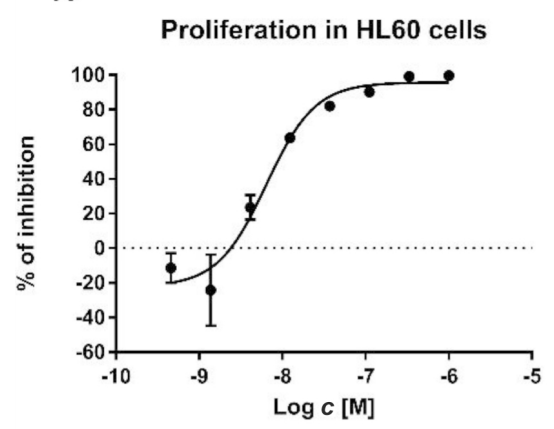

C

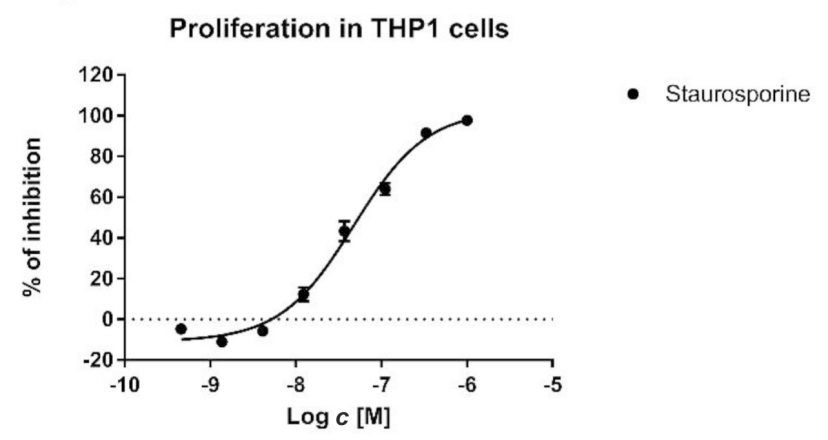

B

Staurosporine

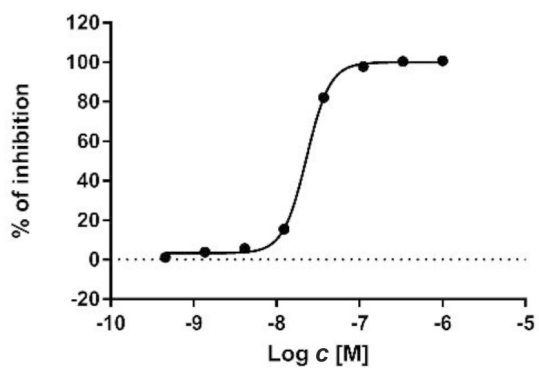

- Staurosporine

Figure 10. Effect of reference compound staurosporine on proliferation of HL60 (A), Jurkat (B) and THP1 (C) cells after $72 \mathrm{~h}$ of incubation $(n=3)$.

tion of proliferation up to $24 \%$ was observed at the highest concentrations of compounds 9 and 11, however only in THP1 cells (Figure 6.). Overall, these findings further support that observed inhibition of TNF $\alpha$ expression is due to compounds activity, rather than the result of toxicity.

\section{Reference Compounds}

In the investigation of the biological activity of the tested compounds 1-32, staurosporine and corticosteroid dexamethasone were used as reference compounds (Figures 10 and 11). Their effects on proliferation of HL60 (A), Jurkat (B) and THP1 (C) cells after $72 \mathrm{~h}$ of incubation (Figure 10) and on IL8 (A) and TNFa (B) production in LPS stimulated PBMC were presented and compared to the effects of the investigated photoproducts. Also, IC $C_{50}$ values determined for reference compounds in cell proliferation assay (staurosporine) and LPS stimulation assay (dexamethasone) are presented in Table 1.

\section{Physico-Chemical Properties}

As an initial attempt for better understanding and explaning the biological activity of compounds 1-32, their physico-chemical properties were also investigated. Experimental lipophilicity, as determined by RP-HPLC was expressed by using chrom $\log D$. These values were in the range 1.897.50 at $\mathrm{pH}$ 7.4. Physico-chemical properties of investigated
A

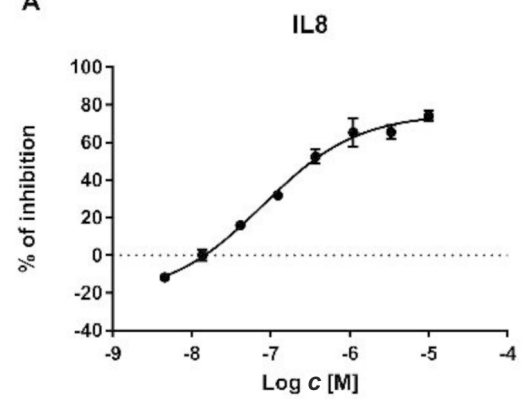

B

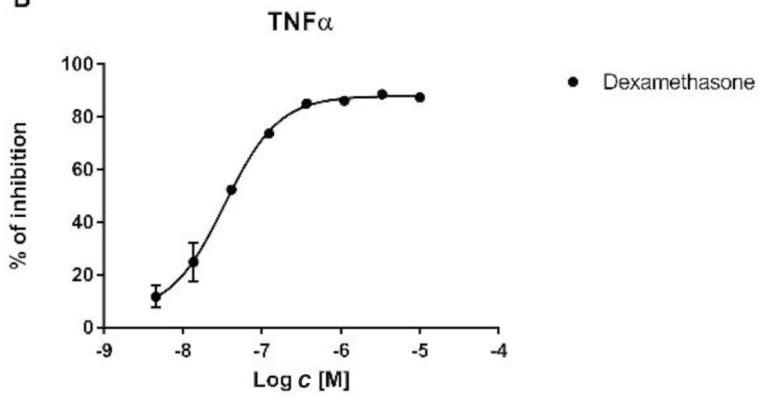

Figure 11. Effect of reference compound dexamethasone on IL8 (A) and TNF $\alpha$ (B) production in LPS stimulated PBMC $(n=2)$. 
Table 1. IC 50 values determined for reference compounds in cell proliferation assay (staurosporine) and LPS stimulation assay (dexamethasone). N/A = compound not tested.

\begin{tabular}{llllll}
\hline Compound & $\mathrm{IC}_{50}$ (HL60) & $\mathrm{IC}_{50}$ (Jurkat) & $\mathrm{IC}_{50}$ (THP1) & $\mathrm{IC}_{50}$ (IL8) & $\mathrm{IC}_{50}$ (TNF $\left.\alpha\right)$ \\
\hline staurosporine & $6.4 \mathrm{nM}$ & $23 \mathrm{nM}$ & $47 \mathrm{nM}$ & $\mathrm{N} / \mathrm{A}$ & $\mathrm{N} / \mathrm{A}$ \\
dexamethasone & $\mathrm{N} / \mathrm{A}$ & $\mathrm{N} / \mathrm{A}$ & $\mathrm{N} / \mathrm{A}$ & $80 \mathrm{nM}$ & $34 \mathrm{nM}$ \\
\hline
\end{tabular}

Table 2. Chrom $\log D$ values determined for some investigated compounds from the following equation: chrom $\log D=0.0857 \times \mathrm{CHI}-2$. Chromatographic Hydrophobic Index $(\mathrm{CHI})$ values have been determined from gradient retention times $(t \mathrm{R})$ at $\mathrm{pH} 7.4$.

\begin{tabular}{cccc}
\hline Compound & CHlaverage & Chrom $\log D$ & $\log P$ \\
\hline $\mathbf{1}$ & 78.70 & 4.74 & 2.88 \\
$\mathbf{2}$ & 81.34 & 4.97 & 2.65 \\
$\mathbf{3}$ & 84.22 & 5.22 & 2.65 \\
$\mathbf{4}$ & 88.05 & 5.55 & 2.97 \\
$\mathbf{5}$ & 89.49 & 5.67 & 2.97 \\
$\mathbf{6}$ & 64.55 & 3.53 & 2.05 \\
$\mathbf{7}$ & 73.18 & 4.27 & 2.9 \\
$\mathbf{8}$ & 74.14 & 4.35 & 2.9 \\
$\mathbf{9}$ & 45.36 & 1.89 & 1.6 \\
$\mathbf{1 1}$ & 45.60 & 1.91 & 1.57 \\
$\mathbf{1 4}$ & 89.01 & 5.63 & 2.97 \\
$\mathbf{2 2}$ & 79.42 & 4.81 & 2.88 \\
$\mathbf{2 3}$ & $>100$ & $>5$ & 3.77 \\
$\mathbf{2 4}$ & 71.26 & 4.11 & 2.58 \\
$\mathbf{2 7}$ & 110.84 & 7.50 & 5.16 \\
$\mathbf{2 8}$ & n/a & n/a & 5.53 \\
$\mathbf{2 9}$ & n/a & n/a & 4.89 \\
\hline
\end{tabular}

compounds have been studied in terms of lipophilicity expressed as chrom $\log D$ values and calculated $\log P$.
Experimental values show that the majority of the investigated compounds are lipophilic (Table 2), which can be favorable in CNS terapeutic area. Correlation between calculated $\log P$ and experimental Chrom $\log D$ values qualitative agreement was observed between calculated $\log P$ and experimental Chrom $\log D$ especially for fused hetero-benzoxazoles $\mathbf{9}$ and $\mathbf{1 1}$ (Table 2), compounds which also inhibited TNF $\alpha$ protein expression in LPS stimulated PBMC (Figure 8), indicating possible antiinflammatory role interesting to further investigate. In case of bicyclo[3.2.1]core correlation between calculated logP and experimental Chrom $\log D$ values did not show good precision in predicting lipophilicity, since Chrom $\log D$ is expected to account for the ionizability of investigated compounds. High-throughput chromatographic determination of lipophilicity enables quick classification of novel compounds. From the group of benzobicyclic compounds 23-32, there are no examples with promising antiinflammatory or antiproliferative activity. These physico-chemical properties and results for biological activity are the reason why these compo-unds are also tested for cholinesterase inhibitory activity and antioxidant characteristics, the benzobicyclo[3.2.1]-derivatives showed better results as potential cholinesterase inhibitors and the oxazole derivatives having better antioxidant properties. ${ }^{[43,44]}$

Even though calculated $\log D$ and $\log P$ values do not show great precision in predicting lipophilicity for analised compounds, it can be used for qualitative prioritization of virtual libraries (Figure 12).

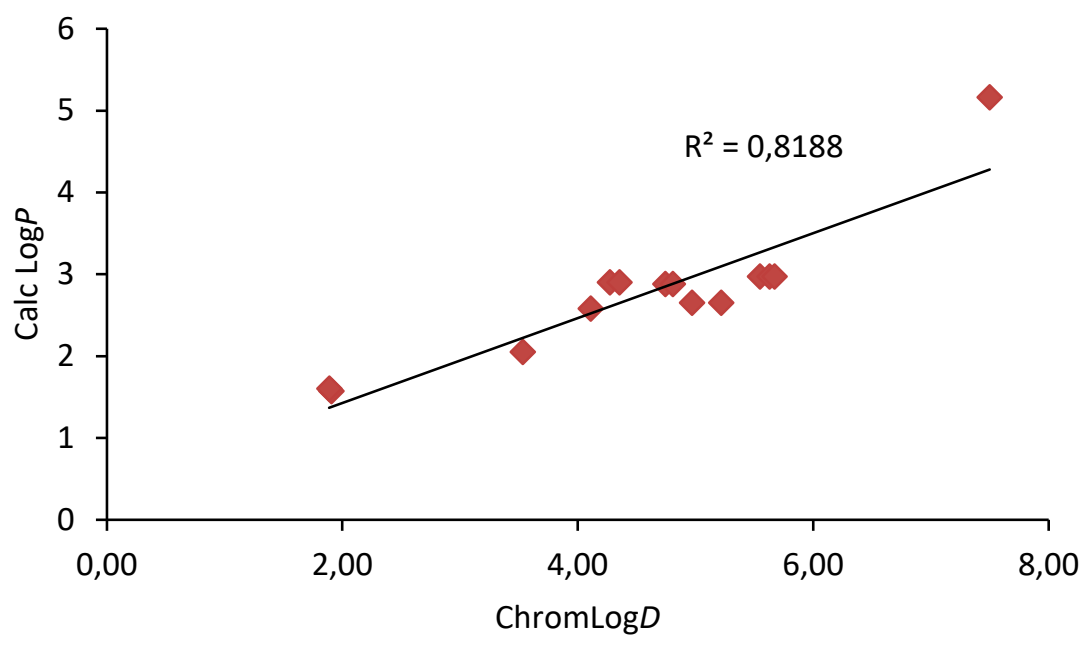

Figure 12. Dependence of Calc $\log P$ on ChromLog $D$ for naphthoxazoles and fused hetero-benzoxazoles 1-9, 11, 14 and 22. 
Most CNS drugs have logP values less than 5 so it is easily absorbed in blood brain barrier where active diffusion of drug is likely to have most lipophilic area like lipid bilayer of membrane and if the value is less than 0 it will move toward hydrophilic compartment like blood serum. For fused hetero-benzoxazoles $\mathbf{9}$ and $\mathbf{1 1}$ it is achieved best correlation between Chrom $\log D$ and $\log P$, but values are low for potential CNS drugs. Compound 29 possessing the benzobicyclo[3.2.1]-octadiene structure has potential to cross BBB using active diffusion.

As the importance of physico-chemical properties of compounds at early stage of discovery of new drugs is now well established, according to the results in this study further investigatons will be performed on the amino derivatives of both groups of compounds. As it was concluded, the similarities in structure and activity of some representative compounds affirm the need to further address their antiinflammatory properties. The starting compound for the synthesis of the amino substituted naphthoxazoles at the defined position will be the chloro derivative $\mathbf{2 0}$, and the chloro derivative $\mathbf{2 8}$ for the group of benzobicyclo[3.2.1]-octadienes. The choliesterase inhibitory activity of those new functional amines will be also investigated in the light of the obtained physico-shemical properties and concerning information about the biological targets and effects predicted by Pass (in silico).

\section{CONCLUSION}

Biological activity of naphthoxazoles 1-5 and 12-22, fused hetero-benzoxazoles 6-11 and benzobicyclo[3.2.1]derivatives 23-32 was investigated in proliferation and inflammation based assays. The tested compounds were prepared by photocylization or photocycloaddition reactions. Several naphthoxazoles and fused heterobenzoxazoles inhibited TNF $\alpha$ protein expression in LPS stimulated PBMC, indicating possible antiinflammatory role which would be interesting to further investigate. Physicochemical properties of tested compounds have been also studied using chromatographic lipophilicity measure, chrom $\log D$ and $\log P$ was calculated as the importance of physico-chemical properties of compounds at early stage of discovery of new drugs is well established. The similarities in structure and activity of some representative compounds affirm the need to further address their antiinflammatory properties.

Acknowledgment. This work was supported by grants from the University of Zagreb short term scientific support for 2018 under the title Synthesis and functionalization of novel (hetero)polycyclic photoproducts and Fidelta Ltd.
Supplementary Information. Supporting information consists of figures showing all investigated effects of both groups of compounds. Supporting information to the paper is attached to the electronic version of the article at: https://doi.org/10.5562/cca3530.

PDF files with attached documents are best viewed with Adobe Acrobat Reader which is free and can be downloaded from Adobe's web site.

\section{REFERENCES}

[1] R. Dua, S. Shrivastava, S. K. Sonwane, S. K. Srivastava, Advan. Biol. Res. 2011, 5, 120-144.

[2] B. Gretzer, N. Maricic, M. Respondek, R. Schuligoi, B. M. Peskar, Br. J. Pharmacol. 2001, 132, 1565-1573. https://doi.org/10.1038/sj.bjp.0703955

[3] E. Huettemann, S. G. Sakka, Current Opinion in Anesthesiol. 2005, 18, 307-314.

https://doi.org/10.1097/01.aco.0000169240.14056.19

[4] H. P. Lipp, J. T. Hartmann, Side Effects of Drugs Annual. 2009, 31, 721-729.

https://doi.org/10.1016/\$0378-6080(09)03145-6

[5] R. E. Norris, P. C. Adamson, Cancer Chemother. Pharmacol. 2010, 65, 1125-1130.

https://doi.org/10.1007/s00280-009-1120-8

[6] a) E. Sobarzo-Sanchez, C. Jullian, B. K. Cassels, C. Saitz, Synth. Commun. 2002, 32, 3687-3693;

https://doi.org/10.1081/SCC-120014990

b) V. S. C. Yeh, Tetrahedron 2004, 60, 11995-12042; https://doi.org/10.1016/j.tet.2004.10.001

c) W. T. Ashton, R. M. Sisco, T. Dong, K. A. Lyons, H. He, G. A. Doss, B. Leiting, R. A. Patel, J. K. Wu, F. Marsilio, N. A. Thornberry, A. E. Weber, Bioorg. Med. Chem. Lett. 2005, 15, 2253-2258;

https://doi.org/10.1016/j.bmcl.2005.03.012

d) M. Voets, I. Antes, Ch. Scherer, U. Mueller-Vieira, K. Biemel, C. Barassin, S. Marchais-Oberwinkler, R. W. Hartmann, J. Med. Chem. 2005, 48, 6632-6642; https://doi.org/10.1021/jm0503704

e) C.-K. Ryu, Ra-Y. Lee, Na Y. Kim, Ae L. Song, Bioorg. Med. Chem. Lett. 2009, 19, 5924-5926;

f) A. Kumar, P. Ahmad, R. A. Maurya, A. B. Singh, A. K. Srivastava, Eur. J. Med. Chem. 2009, 44, 109-116; https://doi.org/10.1016/j.ejmech.2008.03.009

g) E. A. Voight, J. F. Daanen, M. E. Kort, J. Org. Chem. 2010, 75, 8713-8715. https://doi.org/10.1021/jo101938b

[7] A. Abad, C. Agulló, A. C. Cuñat, I. de Alfonso, I. Navarro, N. Vera, Molecules 2004, 9, 287-299. https://doi.org/10.3390/90500287

[8] a) S. Eswaran, A. V. Adhikari, R. A. Kumar, Eur. J. Med. Chem. 2010, 45, 957-966;

https://doi.org/10.1016/j.ejmech.2009.11.036 
b) E. A. da Silva, E. N. da Silva et al., Bioorg. Med. Chem. 2012, 20, 6482-6488.

https://doi.org/10.1016/j.bmc.2012.08.041

[9] D. Kumarm, M. R. Jacob, M. B. Reynolds, S. M. Kerwin, Bioorg. Med. Chem. 2001, 10, 3997-4004. https://doi.org/10.1016/S0968-0896(02)00327-9

[10] X.-Z. Wang, J.-H. Yao, Y.-Y. Xie, G.-J. Lin, H.-L. Huang, Y.-J. Liu, Inorg. Chem. Comm. 2013, 32, 82-88. https://doi.org/10.1016/j.inoche.2013.03.018

[11] a) A. Yu. Mandzhulo, N. A. Mel'nichuk, V. N. Fetyukhin, M. V. Vovka, Russian Journal of Organic Chemistry 2016, 52, 87-91; https://doi.org/10.1134/S1070

b) P. C. Meltzer, P. Blundell, Y. F. Yong, Z. Chen, C. George, M. D. Gonzalez, B. K. Madras, J. Med. Chem. 2000, 43, 2982-2991.

https://doi.org/10.1021/jm000191g

[12] D. Vuk, Ž. Marinić, I. Škorić, Croat. Chem. Acta 2014, 87, 465-473. https://doi.org/10.5562/cca2454

[13] D. Vuk, I. Kikaš, K. Molčanov, O. Horváth, I. Škorić, J. Mol. Struct. 2014, 1063, 83-91.

https://doi.org/10.1016/j.molstruc.2014.01.055

[14] I. Šagud, M. Levačić, Ž. Marinić, I. Škorić, Eur. J. Org. Chem. 2017, 2017, 3787-3794.

https://doi.org/10.1002/ejoc.201700481

[15] a) D. Vuk, D. Potroško, M. Šindler-Kulyk, Ž. Marinić, K. Molčanov, B. Kojić-Prodić, I. Škorić, J. Mol. Struct. 2013, 1051, 1-14;

https://doi.org/10.1016/j.molstruc.2013.07.052

b) A. Ratković, V. Kelava, Ž. Marinić, I. Škorić, J. Mol. Struct. 2019, 1179, 597-607.

https://doi.org/10.1016/j.molstruc.2018.11.057

[16] D. Vidaković, I. Škorić, O. Horváth, Ž. Marinić, M. Šindler-Kulyk, Tetrahedron 2008, 64, 3928-3934. https://doi.org/10.1016/j.tet.2008.02.062

[17] N. I. Fisher, F. M. Hamer, J. Chem. Soc. 1934, 962965. https://doi.org/10.1039/jr9340000962

[18] a) R. D. Desai, R. F. Hunter, A. R. K. Khalidi, J. Chem. Soc. 1938, 321-329;

https://doi.org/10.1039/JR9380000321

b) V. V. Somayajulu, N. V. Subba Rao, Proc. Indian Acad. Sci. Section A 1964, 61, 139-145;

https://doi.org/10.1007/BF03046347

c) J. Moskal, R. Van Stralen, D. Postma, A. M. Van Leusen, Tetrahedron Lett. 1986, 27, 2173-2176; https://doi.org/10.1016/S0040-4039(00)84479-2 d) J. M. Kauffman, P. T. Litak, J. K. Adams, J. Heterocyclic Chem. 1992, 29, 1245-1273.

https://doi.org/10.1002/jhet.5570290534

e) A. R. Katrizky et.al, J. Heterocycl. Chem. 1993, 30, 135-139; https://doi.org/10.1002/jhet.5570300124 f) D. N. Nicolaides, R. Wajih Awad, E. A. Varella, J. Heterocyclic Chem. 1996, 33, 633-637; https://doi.org/10.1002/jhet.5570330318 g) D. N. Nicolaides, R. Wajih Awad, G. K. Papageorgiou, J. Heterocyclic Chem. 1997, 34, 16511656; https://doi.org/10.1002/jhet.5570340602

h) R. A. Novikov, I. P. Klimenko, E. V. Shulishov, V. A. Korolev, Tomilov, V. Yu. Russ. Chem. Bull., Int. Ed. 2008, 57, 1718-1724.

https://doi.org/10.1007/s11172-008-0227-0

[19] I. Šagud, F. Faraguna, Ž. Marinić, M. Šindler-Kulyk, J. Org. Chem. 2011, 76, 2904-2908.

https://doi.org/10.1021/jo1025942

[20] V. Botti, F. Elisei, F. Faraguna, Ž. Marinić, U. Mazzucato, I, Šagud, M. Šindler-Kulyk, A. Spalletti, J. Photochem. Photobiol. A Chem, 2016, 329, 262-272. https://doi.org/10.1016/j.jphotochem.2016.07.009

[21] a) X. Su, Y. Sun, J. Yao, H. Chen, C. Chen, Chem. Commun. 2016, 52, 4537-4540;

https://doi.org/10.1039/C6CC00452K

b) J. Sakata, Y. Ando, K. Ohmori, K. Suzuki, Org. Lett. 2015, 17, 3746-3749;

https://doi.org/10.1021/acs.orglett.5b01732

c) P. S. Jones, P. W. Smith, G. W. Hardy, P. D. Howes, R. J. Upton, R. C. Bethell, Bioorg. Med. Chem. Letters 1999, 9, 605-610;

https://doi.org/10.1016/S0960-894X(99)00032-3 d) M. Nitta, S. Okada, M. Kato, Bull. Chem. Soc. Jpn. 1984, 57, 2463-2467; https://doi.org/10.1246/bcsj.57.2463

e) G. W. Klumpp, J. W. F. K. Barnick, A. H. Veefkind, F. Bickelhaupt, Recueil 1969, 88, 766-768.

[22] M. Šindler-Kulyk, L. Špoljarić, Ž. Marinić, Heterocycles 1989, 29, 679-682.

https://doi.org/10.3987/COM-89-4629

[23] M. Šindler-Kulyk, S. Tomšić, Ž. Marinić, B. Metelko, Recl. Trav. Chim. Pays-Bas 1995, 114, 476-479.

https://doi.org/10.1002/recl.19951141109

[24] M. Šindler-Kulyk, I. Škorić, S. Tomšić, Ž. Marinić, D. Mrvoš-Sermek, Heterocycles 1999, 51, 1355-1369. https://doi.org/10.3987/COM-99-8502

[25] I. Škorić, N. Basarić, Ž. Marinić, M. Šindler-Kulyk, Heterocycles 2001, 55, 1889-1896.

https://doi.org/10.3987/COM-01-9314

[26] N. Basarić, Ž. Marinić, M. Šindler-Kulyk, J. Org. Chem. 2003, 68, 7524-7527.

https://doi.org/10.1021/jo0346454

[27] I. Škorić, N. Basarić, Ž. Marinić, A. Višnjevac, B. KojićProdić, M. Šindler-Kulyk, Chem. Eur. J. 2005, 11, 543551. https://doi.org/10.1002/chem.200401005

[28] I. Škorić, I. Flegar, Ž. Marinić, M. Šindler-Kulyk, Tetrahedron 2006, 62, 7396-7407. https://doi.org/10.1016/j.tet.2006.05.034

[29] I. Škorić, M. Šmehil, Ž. Marinić, K. Molčanov, B. KojićProdić, M. Šindler-Kulyk, J. Photochem. Photobiol. A 2009, 207, 190-196.

https://doi.org/10.1016/j.jphotochem.2009.07.008 
[30] I. Kikaš, I. Škorić, Ž. Marinić, M. Šindler-Kulyk, Tetrahedron 2010, 66, 9405-9414.

https://doi.org/10.1016/j.tet.2010.09.093

[31] I. Škorić, I. Kikaš, M. Kovács, L. Fodor, Ž. Marinić, K. Molčanov, B. Kojić-Prodić, O. Horváth, J. Org. Chem. 2011, 76, 8641-8657. https://doi.org/10.1021/jo200691x

[32] I. Kikaš, O. Horváth, I. Škorić, Tetrahedron Lett. 2011, 52, 6255-6259.

https://doi.org/10.1016/j.tetlet.2011.09.076

[33] I. Kikaš, O. Horváth, I. Škorić, J. Mol. Struct. 2013, 1034, 62-68. https://doi.org/10.1016/j.molstruc.2012.09.005

[34] D. Vuk, O. Horváth, Ž. Marinić, I. Škorić, J. Mol. Struct. 2016, 1107, 70-76.

https://doi.org/10.1016/j.molstruc.2015.11.036

[35] M. Maliepaard, N. J. de Mol, L. H. Janssen, W. van der Neut, W. Verboom, D. N. Reinhoudt, Anticancer Drug Des. 1992, 7, 415-425.

[36] M. J. McKeage, S. J. Berners-Price, P. Galettis, R. J. Bowen, W. Brouwer, L. Ding, L. Zhuang, B. C. Ba-guley, Cancer Chemother. Pharmacol. 2000, 46, 343-350. https://doi.org/10.1007/s002800000166
[37] M. Bajda, S. Boryczka, J. Wietrzyk, B. Malawska, Biomed. Chromatogr. 2007, 21, 123-131.

https://doi.org/10.1002/bmc.706

[38] R. J. Young, D. V. S. Green, C. N. Luscombe, A. P. Hill, Drug Discov. Today 2011, 16, 822-830.

https://doi.org/10.1016/j.drudis.2011.06.001

[39] K. Valkó, C. Bevan, D. Reynolds, Anal. Chem. 1997, 69, 2022-2029.

https://doi.org/10.1021/ac961242d

[40] K. Valkó, Wiley, Holboken, NJ, 2014, pp 450.

[41] K. Valkó, P. Slégel, J. Chromatogr. A 1993, 631, 49-61.

https://doi.org/10.1016/0021-9673(93)80506-4

[42] K. Valko, in: R. T. Borchardt, E. H. Kerns, C. A. Lipinski, D. R. Thakker, B. Wang (Eds.), Biotechnology: Pharmaceutical Aspects, Vol. 1, AAPS Press, 2004, pp 127.

[43] I. Šagud, I. Škorić, F. Burčul, Turk. J. Chem. 2019, 43, 118-124.

https://doi.org/10.3906/kim-1807-133

[44] I. Šagud, I. Škorić, D. Vuk, A. Ratković, F. Burčul, Turk. J. Chem. 2019, 43, 1170-1182.

https://doi.org/10.3906/kim-1903-74 